Research Article

\title{
Patient factors do not predict symptomatic response to botulinum toxin for the treatment of anal fissure
}

\author{
$\operatorname{Kazim~Abbas}^{1}$, Mir Ahmad ${ }^{2}$ \\ ${ }^{1}$ Department of Upper GI Surgery, ${ }^{2}$ Department of Colorectal Surgery, York Hospital, York, UK
}

\author{
Received: 10 April 2016 \\ Revised: 16 April 2016 \\ Accepted: 20 April 2016 \\ *Correspondence: \\ Dr. Kazim Abbas, \\ E-mail: drabbas00@yahoo.com
}

Copyright: ( $)$ the author(s), publisher and licensee Medip Academy. This is an open-access article distributed under the terms of the Creative Commons Attribution Non-Commercial License, which permits unrestricted non-commercial use, distribution, and reproduction in any medium, provided the original work is properly cited.

\begin{abstract}
Background: Botulinum toxin (Botox) is being used increasingly for the treatment of anal fissures despite variable success rates reported in the literature. Our aim was to further characterise the role of patient factors in the response to Botox therapy in order to improve response rates.

Methods: A retrospective case note review of patients who received Botox was performed over a twelve-year period (1999-2011). Responder and non-responder cohorts were compared to identify any differences between groups. Statistical analysis using chi-square and logistic regression analysis were used to compare the groups.

Results: 192 patients were included in study. All patients received Botox injection type A for anal fissure with average dose 40 Units (range 20-80units). A total of 166 of 192 patients in total responded (86.5\% with $71.4 \%$ after the $1^{\text {st }}$ injection and a further $15.1 \%$ after a $2^{\text {nd }}$ Botox injection). Comparison of responder and non-responder cohorts revealed no significant difference in age or gender. Similarly there was no significant difference in the type of fissure, duration of symptoms or position of fissure or prior use of topical therapy.

Conclusions: Botox is effective in the management of anal fissure however patient factors do not appear to predict response to Botox therapy.
\end{abstract}

Keywords: Anal fissure, Botox injection, Patient factors

\section{INTRODUCTION}

Anal fissure is a common condition that can affect all ages and both sexes causes severe perianal discomfort and rectal bleeding. ${ }^{1}$ Although exact mechanisms surrounding the pathophysiology of anal fissures have not been clearly established, current theories revolve around the hyper tonicity of the internal anal sphincter (IAS) and anal blood flow. The hypothesis is that anal fissures are caused by IAS spasm leading to reduced anodermal blood flow and ischaemic ulceration. ${ }^{2,3}$

Treatment of anal fissures involves decreasing the resting IAS pressure. Traditionally this has been by surgical lateral sphincterotomy, which is highly effective in fissure healing at the expense of a risk of faecal incontinence. ${ }^{4}$ This had led to the increasing use alternative methods of reducing IAS pressure. The alternative methods have included the use of topical glycerine trinitrate (GTN) and diltiazem (DTZ) ointments, which cause a relaxation of the IAS.

Botulinum toxin (Botox) is being used increasingly in the treatment of anal fissure as an alternative to surgical lateral sphincterotomy. It is also being seen as an alternative to daily application of topical ointments due to the convenience of a single treatment.

The mechanism of action of Botox appears to be by reducing maximum resting anal pressure (MARP). Studies have shown that Botox produces significantly decreased MARP after injection into the intersphincteric groove or directly into the IAS. In contrast to the mechanism of action of GTN, Botox mediated IAS 
relaxation is by a blockade of sympathetic neural output to the IAS and not by an effect on nitrenergeric transmission. ${ }^{5-7}$

Based on the heterogeneity of the published fissure healing rates in response to Botox, our study aimed to assess fissure-healing rates with the use of Botox and to identify any factors, which were associated with successful outcome.

\section{METHODS}

The outcomes of all patients with anal fissure who had undergone Botox treatment over a twelve-year period (1999-2011) were investigated retrospectively. The identities of all patients who had received Botox were retrieved and patient details including age, gender, duration of symptoms, position of anal fissure and details of previous topical therapy were identified from the case notes.

Patients were classified as either having acute or chronic anal fissures depending on examination findings. Chronic anal fissure was defined as fissure with visible sphincter fibres, anal papillae, sentinel pile, indurated margins and persistent for $>8$ weeks. Acute anal fissure was defined as having deep tear in epithelium of anal margin, but little inflammatory induration or oedema.

All patients underwent day case general anaesthetic procedures during which Botox (Allergan, Marlow, UK) was injected into the IAS either side of the fissure. A total of 40-60U was used depending on surgeon preference.

All patients were followed up in the outpatients department by a consultant or experienced middle grade doctor. Symptoms were assessed by direct questioning and fissure healing was assessed by clinical examination. Patients with on-going symptoms were offered either further Botox treatment or surgical intervention.

Patients were divided into two groups depending on the response to Botox. Responders were defined as patients with symptom resolution following Botox who did not require any further surgical treatment. Non-responders were defined as patients who had on-going symptoms following Botox requiring formal surgical therapy.

\section{Statistical analysis}

A P-value <0.05 was defined as statistically significant. The chi-square test was used to compare variables between responder and non-responder groups. Logistic regression analysis incorporating all the variables was performed.

\section{RESULTS}

A total of 192 patients underwent Botox during the study period. Median follow up was 9 months (Range 2-50 months). Overall, 166 of the 192 patients $(86.5 \%)$ were successfully treated with Botox (responders). 26 patients $(13.5 \%)$ had persistent symptoms and required surgical intervention (non-responders) (Figure 1).

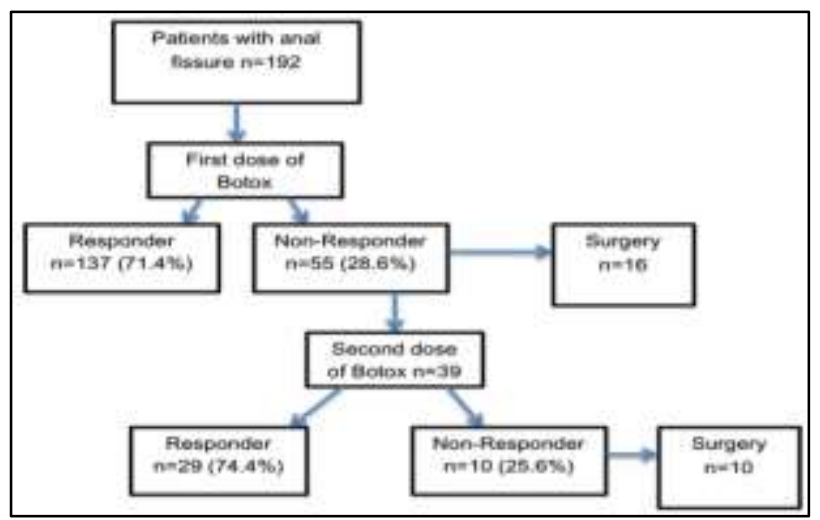

Figure 1: Treatment of patients with anal fissure.

Of the responders $(n=166)$ to Botox, $137(71.4 \%)$ had symptom relief after the $1^{\text {st }}$ Botox injection while 29 $(15.1 \%)$ patients had with on-going symptoms were given a $2^{\text {nd }}$ dose of Botox with complete relief of symptoms. The cumulative response rate was $86.5 \%$.

There was no significant difference in age between responders and non-responders (45.46 versus 44.73, $\mathrm{p}=0.816$ ). Similarly, there was no significant difference in gender, although there was a trend to more females than males in the non-responder group.

Duration of symptoms was grouped into <2, 2-6, 7-12 and $>12$ months. No single duration of symptom had significant effect on response to Botox $(\mathrm{p}=0.892)$ although there was a trend toward better response with duration of symptoms $<6$ months. Prior treatment with topical therapy (GTN/DTZ) prior to Botox did not differ in the responder and non- responder groups. Similarly type of anal fissure (acute, chronic or other) or the position of the fissure (anterior, posterior or both) did not differ between the two groups (Table 1).

The non-responders $(n=26)$ included 15 male and 11 female patients. All patients were subsequently successfully treated surgically. Surgical procedures included lateral sphincterotomy (15 male, 5 female) and advancement flap (4 female) for treatment of resistant anal fissure. One female patient required a 2nd lateral sphincterotomy procedure due to persistent anal fissure. One female patient required advancement flap procedure following lateral sphincterotomy for persistent anal fissure. No complications were reported. No patient had reported persistent pain or discharge on follow up. 
Table 1: Factors affecting the outcome of Botox injection in anal fissure.

\begin{tabular}{|c|c|c|c|c|}
\hline Variables & & Non-responder $\mathrm{N}=26$ (13.5\%) & Responder N=166 (86.5\%) & P Value \\
\hline \multirow{2}{*}{ Age (years) } & $>40$ & $17(8.9)$ & $101(52.6)$ & \multirow{2}{*}{0.658} \\
\hline & $<40$ & $9(4.7)$ & $65(33.9)$ & \\
\hline \multirow{2}{*}{ Gender } & Male & $15(7.8)$ & 76 (39.6) & \multirow{2}{*}{0.258} \\
\hline & Female & $11(5.7)$ & $90(46.9)$ & \\
\hline \multirow{2}{*}{ Type of anal fissure } & Acute & $3(1.6)$ & $29(15.1)$ & \multirow{2}{*}{0.450} \\
\hline & Chronic & $23(12)$ & $137(71.4)$ & \\
\hline \multirow{3}{*}{ Position of anal fissure } & Anterior & $4(2.0)$ & $29(15.1)$ & \multirow{3}{*}{0.877} \\
\hline & Posterior & $18(9.4)$ & $117(60.9)$ & \\
\hline & Both & $4(2.1)$ & $20(10.4)$ & \\
\hline \multirow{4}{*}{ Duration of symptoms } & $<2$ months & $4(2.1)$ & $30(15.6)$ & \multirow{4}{*}{0.892} \\
\hline & 2-6 months & $12(6.3)$ & 67 (34.9) & \\
\hline & 7-12 months & $7(3.7)$ & $42(21.9)$ & \\
\hline & $>12$ months & $3(1.6)$ & $27(14.1)$ & \\
\hline \multirow{2}{*}{$\begin{array}{l}\text { Topical therapy } \\
\text { (GTN/Diltiazem) }\end{array}$} & Yes & $15(7.8)$ & $99(51.6)$ & \multirow{2}{*}{0.851} \\
\hline & No & $11(5.7)$ & $67(34.9)$ & \\
\hline
\end{tabular}

\section{DISCUSSION}

The traditional treatment of anal fissure has been the lateral internal sphincterotomy, which has been reported to have a high success rate. L $^{8}$ Longer-term follow up however reveals that there is a significant risk of longterm continence disturbance. A recent systematic review has demonstrated impaired continence in up to $14 \%$ of patients post sphincterotomy (Long term continence disturbance after lateral internal sphincterotomy for chronic anal fissure; a systematic review and metaanalysis). The use of topical treatments including GTN and DTZ ointments has also been popular but with much lower efficacy compared to surgery. ${ }^{9}$ Given these issues attention has turned to the use of alternative treatments such as Botox.

The reported efficacy of Botox for fissure healing appears to be highly variable. Brisinda et al have reported healing rates of $92 \%$ at in patients treated with Botox compared with $70 \%$ healing in the group treated with topical GTN. ${ }^{6}$ Other studies have not been able to replicate these results, with reported fissure healing rates of $37-74 \%$ with Botox. A recent Cochrane review even concluded that there was no statistical advantage to Botox when compared to GTN. ${ }^{5,7,9-11}$ In contrast, our study has demonstrated that Botox therapy is effective treatment for both acute and chronic anal fissure with a response rate of $86.5 \%$ at a median follow up of 9 months.

Our study has also shown that patient factors including type, duration, position of fissure and prior topical therapy do not appear to significantly influence the response to Botox. The impact of patient factors on the response to Botox is poorly studied. There is some evidence that in patients with anterior or low-pressure fissures there is aberrant response to Botox. In these patients Botox may induce contraction of the IAS or lead to no response with resultant poor healing rates. ${ }^{12}$

A study by Thornton et al assessed the impact of patient factors including age, gender and pain score on fissure healing. As in our study, none of these factors were found to be associated with fissure healing. Patients with a low baseline maximum resting anal pressure had significantly improved fissure healing rates. ${ }^{5}$ A further study by Lindsey at al investigated the effect of fissurectomy and Botox on patients with medically resistant fissure. Again, patient factors including gender, presence of a sentinel pile, and duration of symptoms, fissure position or nature of previous symptoms were not significantly associated with improved healing. ${ }^{13}$ In another study, looking at Botox for anal fissures failing GTN ointment, no significant differences in healing were demonstrated for those with or without underlying cause, duration of symptoms or patient sex. As in our study, a nonsignificant trend to better healing was noted in females and longer duration of symptoms. ${ }^{11}$

Although we have not investigated the dose of Botox use and its effect on fissure healing several other studies have. In a study by Maria et al, long-term healing rates were studied for patients treated initially, with either 15 or 20 units of Botox, patients with non-healing fissures were re-treated with either 20 units or 25 units of Botox. The healing rates were significantly better in the higher dosage group.

Minguez et al and Brisinda et al also report on better results with higher dose of Botox. ${ }^{14-16}$ A recent Cochrane review and meta-analysis concluded however that the neither the dose nor the type of Botox injected altered healing rates. ${ }^{9}$ 


\section{CONCLUSION}

In this study we have demonstrated that Botox is a safe and effective modality for the treatment of both with a cumulative success rate of $86.5 \%$ in a series of 192 patients with a low complication rate. Patients who do not respond to the first dose of Botox have a $74.4 \%$ chance of responding to the second dose. Patient factors do not appear to have a role in the response to Botox and hence it does not appear be possible to target Botox treatment more effectively based on our results.

From our results Botox can be recommended as an effective and safe first line treatment for initial management of anal fissures. Patients who do not respond to the first dose of Botox should be offered a second dose of Botox with reasonable chance of success. Lateral internal sphincterotomy still retains a role in patients who fail Botox and have on-going symptoms. These patients will need to be cautioned with regard to the risk of long-term continence disturbances.

We acknowledge that there are a number of weaknesses in this study. Firstly it is a retrospective study and prone to errors of documentation. We may also be criticized for reporting on symptom relief and not objective fissure healing, however it can be argued that symptom relief is a valid clinical outcome and can be a surrogate for fissure healing.

Funding: No funding sources Conflict of interest: None declared

Ethical approval: The study was approved by the institutional ethics committee

\section{REFERENCES}

1. Lund JN, Scholefield JH. Aetiology and treatment of anal fissure. Br J Surg. 1996;83:1335-44.

2. Gibbons CP, Read NW. Anal hypertonia in fissures; cause or effect? Br J Surg. 1986;73:443-5.

3. Schouten WR, Briel JW, Auwerda JJ. Relationship between anal pressure and anodermal blood flow. The vascular pathogenesis of anal fissures. Dis Colon Rectum. 1994;37:664-9.

4. Nyam DC, Pemberton JH. Long-term results of lateral internal sphincterotomy for chronic anal fissure with particular reference to incidence of fecal incontinence. Dis Colon Rectum. 1999;42:1306-10.

5. Thornton MJ, Kennedy ML, King DW. Prospective manometric assessment of botulinum toxin and its correlation with healing of chronic anal fissure. Dis Colon Rectum. 2005;48:1424-31.
6. Brisinda G, Cadeddu F, Brandara F, Marniga G, Maria G. Randomized clinical trial comparing botulinum toxin injections with 0.2 per cent nitroglycerin ointment for chronic anal fissure. $\mathrm{Br} \mathbf{J}$ Surg. 2007;94:162-7.

7. Jones OM, Ramalingam T, Merrie A, Cunningham C, George BD, Mortensen NJ, et al. Randomized clinical trial of botulinum toxin plus glyceryl trinitrate versus botulinum toxin alone for medically resistant chronic anal fissure: overall poor healing rates. Dis Colon Rectum. 2006;49:1574-80.

8. Nelson RL, Chattopadhyay A, Brooks W, Platt I, Paavana T, Earl S. Operative procedures for fissure in ano. Cochrane Database Syst Rev. 2011;CD002199.

9. Nelson RL, Thomas K, Morgan J, Jones A. Nonsurgical therapy for anal fissure. Cochrane Database Syst Rev. 2012;2:CD003431.

10. Festen S, Gisbertz SS, van Schaagen F, Gerhards MF. Blinded randomized clinical trial of botulinum toxin versus isosorbide dinitrate ointment for treatment of anal fissure. $\mathrm{Br} \quad \mathrm{J}$ Surg. 2009;96:1393-99.

11. Lindsey I, Jones OM, Cunningham C, George BD, Mortensen NJ. Botulinum toxin as second-line therapy for chronic anal fissure failing 0.2 percent glyceryl trinitrate. Dis Colon Rectum. 2003;46:361-6.

12. Lindsey I, Jones OM, Cunningham C. A contraction response of the internal anal sphincter to Botulinum toxin; does low-pressure chronic anal fissure have a different pathophysiology? Colorectal Dis. 2011;13:1014-8.

13. Lindsey I, Cunningham C, Jones OM, Francis C, Mortensen NJ. Fissurectomy-botulinum toxin; a novel sphincter-sparing procedure for medically resistant chronic anal fissure. Dis Colon Rectum. 2004;47:1947-52.

14. Maria G, Brisinda G, Bentivoglio AR, Cassetta E, Gui D, Albanese A. Botulinum toxin injections in the internal anal sphincter for the treatment of chronic anal fissure; long-term results after two different dosage regimens. Ann Surg. 1998;228:664-9.

15. Minguez M, Melo F, Espi A, García-Granero E, Mora F, Lledó S, et al. Therapeutic effects of different doses of botulinum toxin in chronic anal fissure. Dis Colon Rectum. 1999;42:1016-21.

16. Brisinda G, Maria G, Sganga G, Bentivoglio AR, Albanese A, Castagneto M. Effectiveness of higher doses of botulinum toxin to induce healing in patients with chronic anal fissures. Surgery. 2002;131:179-84.

Cite this article as: Abbas K, Ahmad M. Patient factors do not predict symptomatic response to botulinum toxin for the treatment of anal fissure. Int Surg J 2016;3:484-7. 